\title{
Orthogonal Experimental Studies on Preparation of Mine-Filling Materials from Carbide Slag, Granulated Blast-Furnace Slag, Fly Ash, and Flue-Gas Desulphurisation Gypsum
}

\author{
Mingyue Wu $\mathbb{D}^{D}$, Xiangming Hu ${ }^{(D)}$, Qian Zhang, Weimin Cheng, and Zunxiang Hu \\ Key Lab of Mine Disaster Prevention and Control, College of Mining and Safety Engineering, \\ Shandong University of Science and Technology, Qingdao 266590, China \\ Correspondence should be addressed to Xiangming Hu; xiangming0727@163.com
}

Received 1 April 2018; Accepted 24 June 2018; Published 9 August 2018

Academic Editor: Marco Cannas

Copyright ( 2018 Mingyue Wu et al. This is an open access article distributed under the Creative Commons Attribution License, which permits unrestricted use, distribution, and reproduction in any medium, provided the original work is properly cited.

Environmentally friendly and cheap composite green cementitious materials have been prepared from carbide slag, fly ash, fluegas desulphurisation (FGD) gypsum, and granulated blast-furnace slag (GBFS) without using cement clinker. Orthogonal testing was used to investigate the effects of the raw materials on the amount of water required for reaching standard consistency and consistency, setting time, slump value, and strength of the produced materials after curing for $7 \mathrm{~d}$ and $28 \mathrm{~d}$. Scanning electron microscopy (SEM) and X-ray diffraction (XRD) techniques were used for the analysis of the sample microstructure and hydration products as well as for the exploration of possible hydration mechanisms. We found that, among the utilised raw materials, the addition of FGD gypsum had the most significant effect on the setting time and amount of water required for reaching standard consistency and consistency, while the addition of GBFS deeply affected the slump value. The optimal activation results were obtained when the mass ratio of carbide slag: fly ash: GBFS : FGD gypsum was equal to $12.1: 60.6: 18.2: 9.1$.

\section{Introduction}

Owing to the increasing depletion of nonrenewable resources and effects produced by global warming, the high levels of energy consumption and pollution generated during the production of cement clinker have attracted widespread concern. Therefore, both domestic and international scholars are currently attempting to identify high-performance cementitious materials, whose production involves low levels of pollution and energy consumption. Recovering solid waste represents one of the major methods for manufacturing such "green" cementitious materials. The utilised waste typically includes fly ash (the fine ash collected from the soot produced during coal combustion), which exhibits a pozzolanic effect and can be activated in an alkaline environment. Another solid waste material consists of granulated slag (or waterquenched blast-furnace slag), which can potentially exhibit hydraulic cementitious properties. The major component of FGD gypsum is calcium sulphate dihydrate. At present, these industrial wastes are primarily utilised for the production of cement $[1,2]$, concrete [3-7], geopolymers [8-10], and cementitious materials for mine filling $[11,12]$. For example, $\mathrm{Ma}$ et al. [13] prepared sulphoaluminate cement that was capable of meeting special structural requirements from fly ash and FGD gypsum. Sarkar et al. [14] partially substituted cement with fly ash and GBFS to investigate variations in the concrete strength and determine the optimal ratio of the utilised components. Qin et al. [15] prepared a hydraulic cementitious material using GBFS, FGD gypsum, and activators as raw materials. According to the results of these studies, the hydration reaction that occurs between fly ash, GBFS, and FGD gypsum can be used for the preparation of cementitious materials. However, in all the studies on the utilisation of solid wastes such as fly ash and GBFS, a certain amount of cement clinker was added during production, thus reducing the economic benefits of the proposed method.

Carbide slag is a waste residue produced during the hydrolysis of calcium carbide; its major components include calcium oxide and calcium hydroxide. Without special treatment, a large amount of carbide slag produces dust and 
air pollution. Additionally, if carbide slag is stacked, it may occupy a large area of the land and put immense pressure on the ecological environment. Hence, both domestic and international researchers have conducted a number of studies on the comprehensive utilisation of carbide slag. Wang et al. [16] prepared cement clinker using carbide slag as the raw material and studied the formation process of cement clinker minerals. Hao et al. [17] examined the effects of the fly ash and carbide slag addition on the compressive strength of the resulting cement paste. However, it is still unclear whether carbide slag can effectively activate fly ash. Because carbide slag is rich in the alkaline calcium oxide and calcium hydroxide components, we hypothesised that it would provide a large number of $\mathrm{OH}^{-}$ions when used as an admixture of cementitious materials. These ions can effectively destroy the acidic film formed on the surfaces of fly ash and GBFS particles, leading to the dissolution of various mineral constituents, such as silicon dioxide and aluminium oxide. The latter process in turn promotes the hydration of fly ash and GBFS components and forms hydration products characterised by a certain level of strength.

Hence, in the present study, fly ash, carbide slag, GBFS, and FGD gypsum were used to prepare green cementitious materials without cement clinker. Afterwards, we investigated the mechanical properties and morphology of these materials in order to identify the optimal quantities of carbide slag, fly ash, and other industrial waste components. We hope that this study will contribute to the preparation and promotion of high-quality inexpensive cementitious materials for mine filling [18-24].

\section{Materials and Methods}

2.1. Raw Materials. The following raw materials have been utilised in this study.

Fly ash with a density of $1.78 \mathrm{~g} / \mathrm{cm}^{3}$ and a specific surface area of $219 \mathrm{~m}^{2} / \mathrm{kg}$ was purchased from Shandong Binzhou Shanshui Cement Co., Ltd. Its activity index was calculated as follows:

$$
R_{28}=\left(\frac{R}{R_{0}}\right) \times 100 \% .
$$

The obtained activity index of the fly ash was $\mathrm{H}_{28}=61 \%$ (its chemical composition is listed in Table 1).

GBFS with a density of $2.88 \mathrm{~g} / \mathrm{cm}^{3}$ and a specific surface area of $361 \mathrm{~m}^{2} / \mathrm{kg}$ was purchased from Shandong Binzhou Shanshui Cement Co., Ltd. Its chemical composition is listed in Table 1, and the corresponding X-ray diffraction (XRD) pattern is depicted in Figure 1. It shows the existence of a large peak in the $2 \theta$ range of $20-38^{\circ}$ and a very small amount of the gehlenite phase without any distinct crystalline peaks. Hence, the GBFS used in this study can be considered a completely vitreous material.

Carbide slag purchased from Shandong Linzi Acetylene Gas Factory was calcined for $30 \mathrm{~min}$ at $1000^{\circ} \mathrm{C}$. It was characterised by the calcium oxide mass fraction of $77.5 \%$, calcium hydroxide mass fraction of $18.5 \%$, density of $2.64 \mathrm{~g} / \mathrm{cm}^{3}$, and specific surface area of $419 \mathrm{~m}^{2} / \mathrm{kg}$. The chemical composition of the utilised carbide slag is listed in Table 1.

FGD gypsum that contained more than 90 mass\% of calcium sulphate dihydrate was purchased from Shandong Binzhou Shanshui Cement Co., Ltd. After the calcination of FGD gypsum for $2 \mathrm{~h}$ at $180^{\circ} \mathrm{C}$, its major component was converted into $\beta$-hemihydrate gypsum with a density of $2.64 \mathrm{~g} / \mathrm{cm}^{3}$ and a specific surface area of $269 \mathrm{~m}^{2} / \mathrm{kg}$.

Admixtures of sodium hydroxide ( $\geq 96.0$ mass $\%)$ and naphthalene superplasticiser $\left(\mathrm{Cl}^{-}\right.$content $<0.4$ mass $\%$, sulphate content $<9$ mass $\%$, and solid content $\geq 93$ mass $\%$ ) were purchased from Chenqi Chemical Technology Co. Ltd., Shanghai.

The density of the mixture was $2.31 \mathrm{~g} / \mathrm{cm}^{3}$, and its specific surface area was $327 \mathrm{~m}^{2} / \mathrm{kg}$.

Round siliceous river sand with a silicon dioxide content exceeding 98 mass\% was utilised. Its particle size is listed in Figure 2.

Tap water was used in all experiments.

2.2. Preparation of Test Blocks. An orthogonal experimental design was employed for the development of experimental procedures. The orthogonal testing parameters included the masses of FGD gypsum (A), GBFS (B), and carbide slag (C) (their corresponding amounts are listed in Table 2).

In accordance with the parameter combinations described in the $\mathrm{L}_{25}\left(5^{6}\right)$ orthogonal table [11], the fly ash, carbide slag, FGD gypsum, GBFS, and admixture components were mixed together to form composite cementitious materials. Prior to mixing, the materials were weighed with an accuracy of $0.01 \mathrm{~g}$ using an electronic balance (YP1002N; Shanghai Jingke Tianmei Scientific Instrument Co., Ltd.) in accordance with the material mixing ratios provided in Table 3. The cement/sand ratio was 0.25 , and the water/cement ratio was 0.5 . Subsequently, the weighed materials were mixed using the following procedure: first, a specified amount of granular sodium hydroxide was dissolved in water, and the resulting aqueous sodium hydroxide solution was added to the bowl of the mixer with a capacity of $5 \mathrm{~L}$ (JJ-5; Wuxi Xiyi Building Materials Instrument Co., Ltd.), which was fixed onto its frame and raised to a set position. Afterwards, the materials were immediately mixed for $30 \mathrm{~s}$ at a low speed of $140 \pm 5 \mathrm{rpm}$. Sand was continuously added at a uniform rate during the next $30 \mathrm{~s}$ of mixing. After the sand addition, the mixer was run for another $30 \mathrm{~s}$ at a high speed of $285 \pm 10 \mathrm{rpm}$ and then stopped for $90 \mathrm{~s}$. Within the first $15 \mathrm{~s}$ after the mixer was stopped, the mortar that had adhered to the blades and bowl wall was scraped into the centre of the bowl. After a $90 \mathrm{~s}$ interval, the mixing process was continued for another $60 \mathrm{~s}$ at a high speed. Immediately after mixing, the materials were moulded using an empty test mould (with dimensions of $40 \mathrm{~mm} \times 40 \mathrm{~mm} \times 160 \mathrm{~mm}$ ) and a bushing fixed onto a vibrating compaction table. A scoop was used to obtain mortar from the mixer bowl, which was placed into the test mould in two layers. About $300 \mathrm{~g}$ of mortar was put into each groove in the first layer, which was then compacted via 60 vibrations. The second layer was added until the mould was filled, and the mortar was again compacted by 60 vibrations. Afterwards, the mould bushing was removed, and the test mould was transferred from the vibrating compaction table. 
TABLe 1: Chemical compositions of raw materials (in wt.\%).

\begin{tabular}{|c|c|c|c|c|c|c|c|}
\hline Raw materials & Loss on ignition & $\begin{array}{l}\text { Silicon } \\
\text { dioxide }\end{array}$ & $\begin{array}{l}\text { Aluminium } \\
\text { oxide }\end{array}$ & Iron(III) oxide & Calcium oxide & $\begin{array}{l}\text { Magnesium } \\
\text { oxide }\end{array}$ & $\begin{array}{l}\text { Sulphur } \\
\text { trioxide }\end{array}$ \\
\hline Fly ash & 4.22 & 45.98 & 31.79 & 6.18 & 3.67 & 0.90 & 0.70 \\
\hline Carbide slag & 1.7 & 3.16 & 2.72 & 0.42 & 64.57 & 0.72 & 1.52 \\
\hline GBFS & 0.25 & 30.13 & 17.14 & 0.71 & 38.83 & 7.38 & 0.59 \\
\hline
\end{tabular}

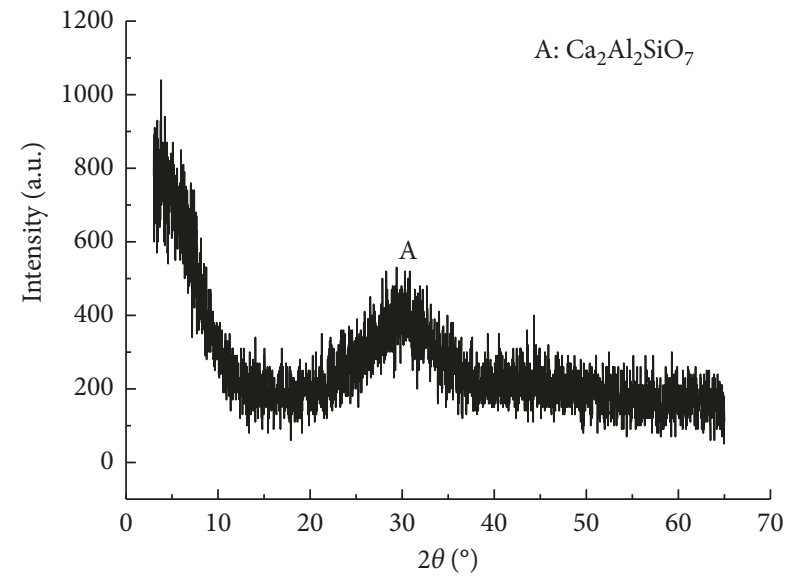

Figure 1

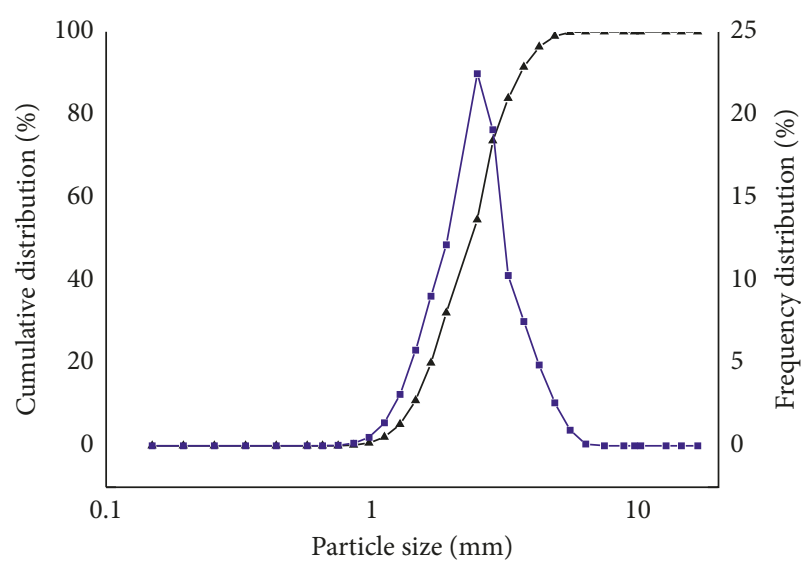

FIGURE 2

TABLE 2: Levels and factors of the orthogonal test.

\begin{tabular}{lccc}
\hline Levels & \multicolumn{3}{c}{ Factors } \\
& $\begin{array}{c}\text { FGD } \\
\text { gypsum (g) (A) }\end{array}$ & GBFS (g) (B) & $\begin{array}{c}\text { Carbide } \\
\text { slag (g) (C) }\end{array}$ \\
\hline 1 & 7 & 24 & 12 \\
2 & 9 & 26 & 14 \\
3 & 11 & 28 & 16 \\
4 & 13 & 30 & 18 \\
5 & 15 & 32 & 20 \\
\hline
\end{tabular}

Any mortar exceeding the dimensions of the test mould was scraped away using a metal ruler, and the produced test block was numbered. The moulded test block was cured at a temperature of $20 \pm 2^{\circ} \mathrm{C}$ in the environment with a relative humidity greater than $50 \%$. After $24 \mathrm{~h}$ of curing, the mould was
TABLE 3: Materials proportioning of the orthogonal test.

\begin{tabular}{|c|c|c|c|c|c|c|}
\hline \multirow[b]{2}{*}{ Number } & \multicolumn{6}{|c|}{ Raw materials } \\
\hline & $\begin{array}{c}\text { FGD } \\
\text { gypsum } \\
\text { (g) }\end{array}$ & $\begin{array}{c}\text { GBFS } \\
(\mathrm{g})\end{array}$ & $\begin{array}{l}\text { Carbide } \\
\text { slag (g) }\end{array}$ & $\begin{array}{l}\text { Fly } \\
\text { ash } \\
\text { (g) }\end{array}$ & $\begin{array}{l}\text { Sodium } \\
\text { hydroxide } \\
\text { (g) }\end{array}$ & $\begin{array}{c}\text { Water- } \\
\text { reducing } \\
\text { admixture } \\
(\mathrm{g})\end{array}$ \\
\hline 1 & 7 & 24 & 12 & 100 & 7.5 & 0.5 \\
\hline 2 & 7 & 26 & 14 & 100 & 7.8 & 0.5 \\
\hline 3 & 7 & 28 & 16 & 100 & 7.9 & 0.5 \\
\hline 4 & 7 & 30 & 18 & 100 & 8.2 & 0.5 \\
\hline 5 & 7 & 32 & 20 & 100 & 8.4 & 0.5 \\
\hline 6 & 9 & 24 & 14 & 100 & 7.7 & 0.5 \\
\hline 7 & 9 & 26 & 16 & 100 & 7.9 & 0.5 \\
\hline 8 & 9 & 28 & 18 & 100 & 8.2 & 0.5 \\
\hline 9 & 9 & 30 & 20 & 100 & 8.4 & 0.5 \\
\hline 10 & 9 & 32 & 12 & 100 & 8.1 & 0.5 \\
\hline 11 & 11 & 24 & 16 & 100 & 7.9 & 0.5 \\
\hline 12 & 11 & 26 & 18 & 100 & 8.2 & 0.5 \\
\hline 13 & 11 & 28 & 20 & 100 & 8.4 & 0.5 \\
\hline 14 & 11 & 30 & 12 & 100 & 8.1 & 0.5 \\
\hline 15 & 11 & 32 & 14 & 100 & 8.3 & 0.5 \\
\hline 16 & 13 & 24 & 18 & 100 & 8.2 & 0.5 \\
\hline 17 & 13 & 26 & 20 & 100 & 8.4 & 0.5 \\
\hline 18 & 13 & 28 & 12 & 100 & 8.1 & 0.5 \\
\hline 19 & 13 & 30 & 14 & 100 & 8.3 & 0.5 \\
\hline 20 & 13 & 32 & 16 & 100 & 8.5 & 0.5 \\
\hline 21 & 15 & 24 & 20 & 100 & 8.4 & 0.5 \\
\hline 22 & 15 & 26 & 12 & 100 & 8.1 & 0.5 \\
\hline 23 & 15 & 28 & 14 & 100 & 8.3 & 0.5 \\
\hline 24 & 15 & 30 & 16 & 100 & 8.5 & 0.5 \\
\hline 25 & 15 & 32 & 18 & 100 & 9.2 & 0.5 \\
\hline
\end{tabular}

removed and subjected to another curing procedure at $20 \pm 2^{\circ} \mathrm{C}$ inside the curing chamber with a relative humidity of $95 \%$. Each test block was cured for either 7 or $28 \mathrm{~d}$, and its strength was measured after the corresponding curing period.

\subsection{Testing Parameters}

2.3.1. Amount of Water and Setting Time Required for Reaching Standard Consistency. According to the BS EN (British Standard European Norm) 196-3 standard (compliant with the EN (European Norm) 196-3 standard), Vicat's apparatus (purchased from Shanghai Shenrui Test Equipment Manufacturing Co., Ltd.) was used to determine the amount of water and setting time required for the cementitious materials to achieve standard consistency.

2.3.2. Consistency. An SC-145 mortar consistometer (purchased from Beijing Zhongke Luda Instrument Co., Ltd.; Figure 3) was used to determine the consistencies of the 


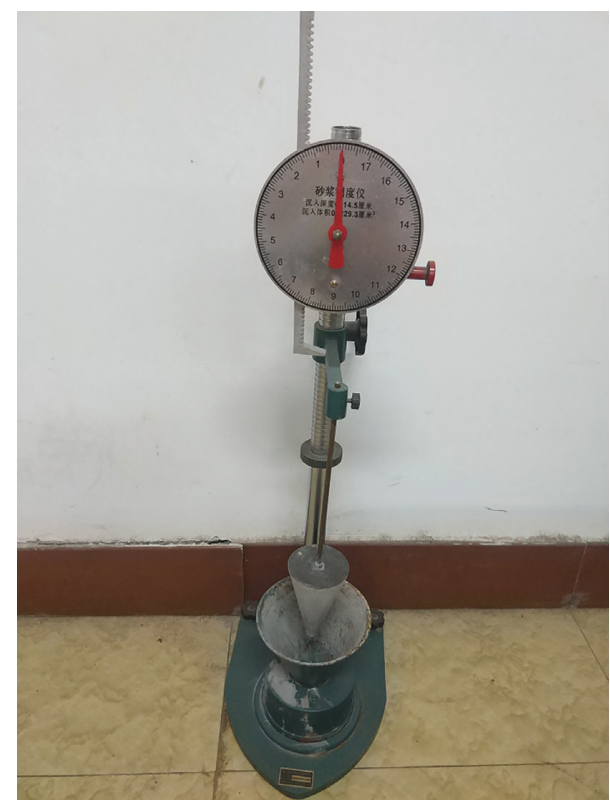

FIGURE 3

produced cementitious materials. First, each prepared cementitious material was placed inside a container. When the tip of the testing cone touched the material surface, the clamping screw was unscrewed, allowing the testing cone to fall freely. The falling depth displayed on the consistometer dial corresponded to the consistency value for the cementitious material (the results of three tests were averaged for each studied cementitious material), and the measurement accuracy was $1 \mathrm{~mm}$.

2.3.3. Slump Testing. The cementitious material was packed inside a tube in three layers with approximately equal volumes. Each layer was treated with a tamping rod evenly inserted in the slump cylinder 25 times following the shape of a spiral. After the completion of the tamping process, the slump tube was removed, and the difference between the centre point of the specimen's top and the height of the produced slump (corresponding to the slump value) was measured by a steel ruler. The duration of the entire testing procedure was about $150 \mathrm{~s}$, and the accuracy of the obtained results was $1 \mathrm{~mm}$. If the studied sample exhibited collapse or shear, the results of the slump test were considered negative, and the testing procedure was repeated.

2.3.4. Strength. Compressive and flexural strengths (Figure 4) of the cementitious materials were measured in accordance with the BS EN (British Standard European Norm) 196-1 standard compliant with the EN (European Norm) 196-1 standard.

2.3.5. XRD Analysis. After the test blocks were cured for 7 and $28 \mathrm{~d}$, the surfaces that might be possibly carbonated were removed with a knife. The samples were removed from the interior of each test block and cut into $2.5-5 \mathrm{~mm}$ pieces [25], which were subsequently immersed in a mixture of absolute ethanol and acetone. After the hydration reaction was complete, the test blocks were dried for about $48 \mathrm{~h}$ at $40^{\circ} \mathrm{C}$ and then ground into fine powder for XRD analysis.

2.3.6. Scanning Electron Microscopy Analysis. After the test blocks were cured for 7 and $28 \mathrm{~d}$, additional samples were taken from their interior and cut into $2.5-5 \mathrm{~mm}$ pieces [26], which were subsequently dried to a constant weight in a vacuumdrying tube with a vacuum degree of $740 \mathrm{~mm} \mathrm{Hg}$ at $60^{\circ} \mathrm{C} \mathrm{[27].}$ Afterwards, the samples were metallised under vacuum, placed into a scanning electron microscope (SEM; SX-40; International Scientific Instruments, Japan) for the observation of their cross-sectional morphology, and photographed.

\section{Results and Discussion}

3.1. Amounts of Water Required for Reaching Standard Consistency and Consistency. Table 4 lists the results of orthogonal testing. Table S1 contains the results of range analysis, which was conducted to determine the amounts of water required for reaching standard consistency and consistency of the cementitious materials. According to the results presented in Table $\mathrm{S} 1$, when the raw material combination is $\mathrm{A}_{5} \mathrm{~B}_{2} \mathrm{C}_{4}$ (corresponding to the mass ratio of FGD gypsum: GBFS : carbide slag equal to $15: 26: 18$ ), it exhibits the greatest impact on the amounts of water required for reaching standard consistency (the greater the content of FGD gypsum, the higher the amount of the consumed free water; in addition, carbide slag consumes a fraction of free water as well). When the raw material combination is $\mathrm{A}_{2} \mathrm{~B}_{1} \mathrm{C}_{5}$ (corresponding to the FGD gypsum: GBFS : carbide slag mass ratio of $9: 24: 20$ ), it exhibits the greatest impact on the consistency of cementitious materials since carbide slag not only consumes large amounts of free water but also releases a lot of heat that accelerates the hydration reaction. As shown in Figure 5, the raw materials can be ranked in terms of their effect on the amount of water required to achieve standard consistency and consistency as follows: FGD gypsum $>$ carbide slag $>$ GBFS. After high-temperature calcination, the major components of the tested FGD gypsum and carbide slag were transformed into hemihydrate gypsum and calcium oxide, respectively. Once hemihydrate gypsum was exposed to water, it was hydrated rapidly to produce dihydrate gypsum. A large amount of free water was consumed during hydration, while calcium oxide species also reacted with water to generate calcium hydroxide. The amounts of water required for the cementitious materials to reach standard consistency varied, owing to the large volume of consumed free water (in general, consistency is a measure of the fluidity of a cementitious system corresponding to a fixed volume of water). The samples containing large amounts of FGD gypsum and carbide slag consume more free water, thus decreasing the consistency and fluidity of the cementitious system.

3.2. Setting Time. Table S2 contains the results of the range analysis conducted for the setting time of the prepared cementitious materials. It shows that when the combinations of the raw materials correspond to the formulas $A_{1} B_{5} C_{5}$ and $\mathrm{A}_{1} \mathrm{~B}_{5} \mathrm{C}_{3}$ (for the mass ratios of FGD gypsum : GBFS : carbide slag 


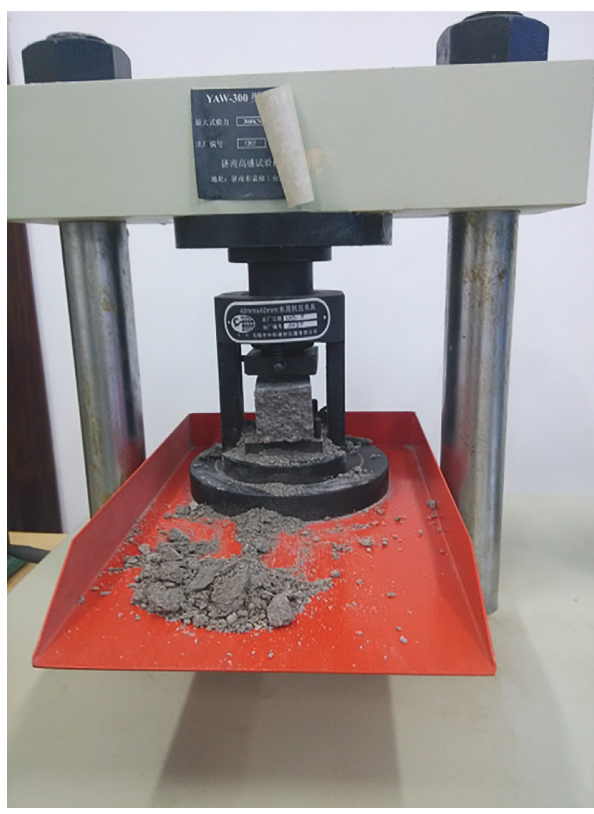

(a)

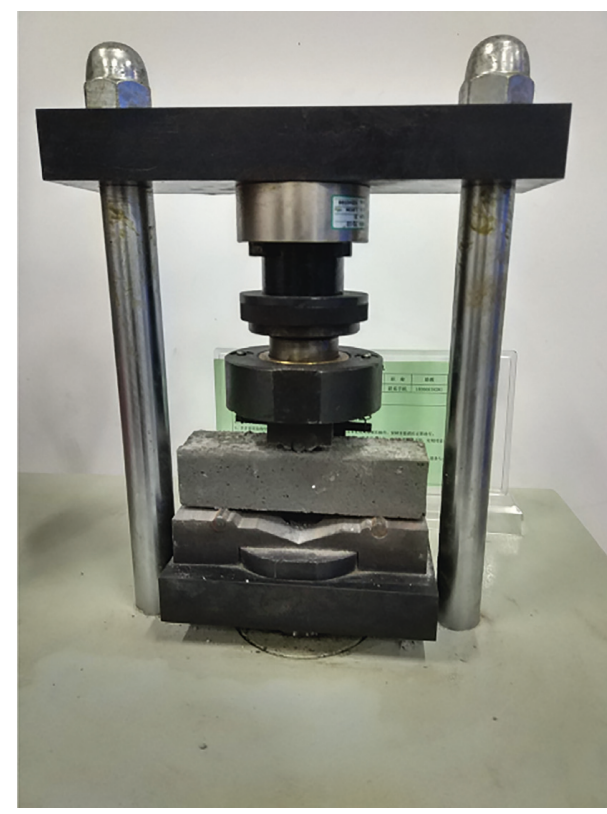

(b)

Figure 4

TABLE 4: Results of the orthogonal test.

\begin{tabular}{|c|c|c|c|c|c|c|c|c|c|}
\hline \multirow[b]{2}{*}{ Number } & \multirow{2}{*}{$\begin{array}{l}\text { Water required } \\
\text { for standard } \\
\text { consistency }(\mathrm{mL})\end{array}$} & \multirow[b]{2}{*}{$\begin{array}{l}\text { Consistency } \\
(\mathrm{mm})\end{array}$} & \multirow{2}{*}{$\begin{array}{l}\text { Slump } \\
(\mathrm{mm})\end{array}$} & \multicolumn{2}{|c|}{ Setting time (min) } & \multicolumn{2}{|c|}{$7 \mathrm{~d}$ strength $(\mathrm{MPa})$} & \multicolumn{2}{|c|}{$28 \mathrm{~d}$ strength $(\mathrm{MPa})$} \\
\hline & & & & $\begin{array}{c}\text { Initial } \\
\text { time }\end{array}$ & $\begin{array}{l}\text { Final } \\
\text { time }\end{array}$ & $\begin{array}{c}\text { Compressive } \\
\text { strength }\end{array}$ & $\begin{array}{l}\text { Flexural } \\
\text { strength }\end{array}$ & $\begin{array}{c}\text { Compressive } \\
\text { strength }\end{array}$ & $\begin{array}{l}\text { Flexural } \\
\text { strength }\end{array}$ \\
\hline 1 & 141 & 14 & 212 & 287 & 397 & 1.72 & 0.61 & 3.79 & 1.35 \\
\hline 2 & 137 & 13 & 143 & 298 & 387 & 1.81 & 0.65 & 3.40 & 1.05 \\
\hline 3 & 128 & 14 & 129 & 265 & 389 & 2.48 & 0.95 & 3.67 & 1.12 \\
\hline 4 & 132 & 13 & 144 & 267 & 364 & 1.78 & 0.64 & 3.23 & 0.98 \\
\hline 5 & 135 & 14 & 165 & 279 & 397 & 2.14 & 0.80 & 3.36 & 1.33 \\
\hline 6 & 126 & 14 & 138 & 259 & 367 & 2.22 & 0.84 & 3.20 & 1.30 \\
\hline 7 & 143 & 13 & 174 & 246 & 387 & 1.94 & 0.79 & 2.92 & 1.29 \\
\hline 8 & 136 & 14 & 158 & 275 & 376 & 2.32 & 0.92 & 3.84 & 1.44 \\
\hline 9 & 134 & 15 & 149 & 289 & 359 & 2.37 & 0.93 & 3.46 & 1.23 \\
\hline 10 & 137 & 14 & 190 & 273 & 378 & 2.43 & 0.93 & 3.39 & 1.24 \\
\hline 11 & 127 & 11 & 147 & 256 & 367 & 1.89 & 0.77 & 3.35 & 1.17 \\
\hline 12 & 147 & 12 & 211 & 265 & 387 & 1.90 & 0.78 & 3.13 & 1.14 \\
\hline 13 & 132 & 15 & 157 & 286 & 398 & 1.84 & 0.75 & 3.14 & 1.26 \\
\hline 14 & 123 & 14 & 138 & 265 & 369 & 1.81 & 0.72 & 3.56 & 1.24 \\
\hline 15 & 128 & 14 & 139 & 254 & 378 & 2.22 & 0.83 & 3.37 & 1.03 \\
\hline 16 & 131 & 12 & 210 & 247 & 367 & 1.82 & 0.66 & 3.49 & 1.33 \\
\hline 17 & 138 & 14 & 200 & 267 & 373 & 2.29 & 0.90 & 4.07 & 1.40 \\
\hline 18 & 121 & 13 & 129 & 256 & 357 & 1.80 & 0.66 & 3.56 & 1.10 \\
\hline 19 & 127 & 13 & 146 & 243 & 363 & 1.50 & 0.66 & 3.40 & 0.98 \\
\hline 20 & 130 & 13 & 178 & 287 & 356 & 2.15 & 0.80 & 4.05 & 1.47 \\
\hline 21 & 145 & 13 & 191 & 267 & 364 & 1.63 & 0.57 & 3.58 & 1.16 \\
\hline 22 & 138 & 9 & 159 & 253 & 352 & 1.63 & 0.56 & 3.47 & 1.15 \\
\hline 23 & 146 & 8 & 148 & 256 & 358 & 1.71 & 0.61 & 3.94 & 1.40 \\
\hline 24 & 141 & 9 & 149 & 278 & 398 & 1.81 & 0.66 & 3.47 & 1.15 \\
\hline 25 & 142 & 7 & 138 & 298 & 378 & 1.77 & 0.70 & 3.72 & 1.22 \\
\hline
\end{tabular}

of $7: 15: 20$ and $7: 15: 16$, resp.), the initial and final setting times are affected most significantly because FGD gypsum inhibits the hydration process of cementitious materials. As shown in Figure 6, the raw materials can be ranked in terms of their effect on the initial and final setting times as follows: FGD gypsum $>$ carbide slag $>$ GBFS. In general, the setting time of cementitious materials is related to their hydration rate. Dihydrate gypsum, a hydration product of hemihydrate gypsum, can 


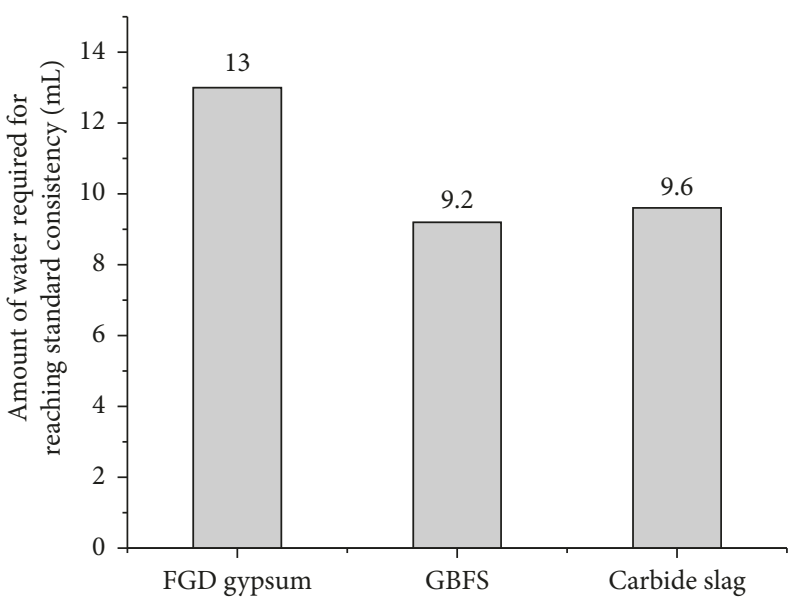

(a)

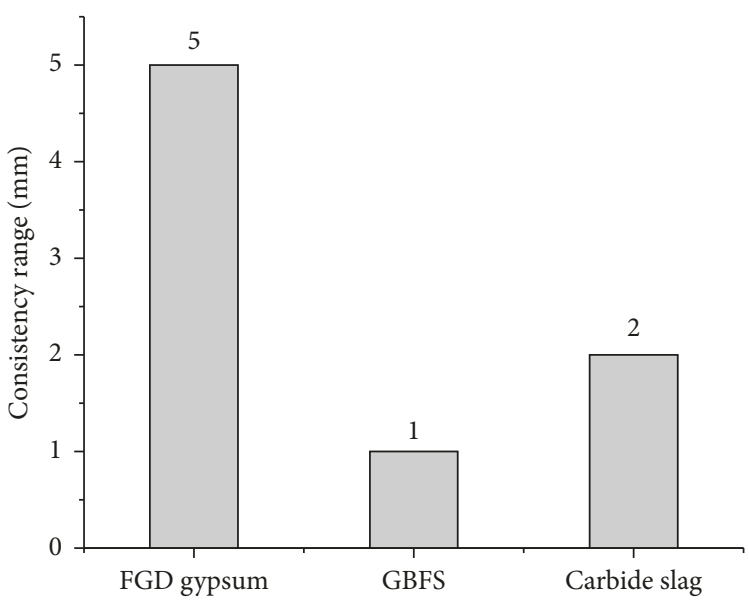

(b)

Figure 5

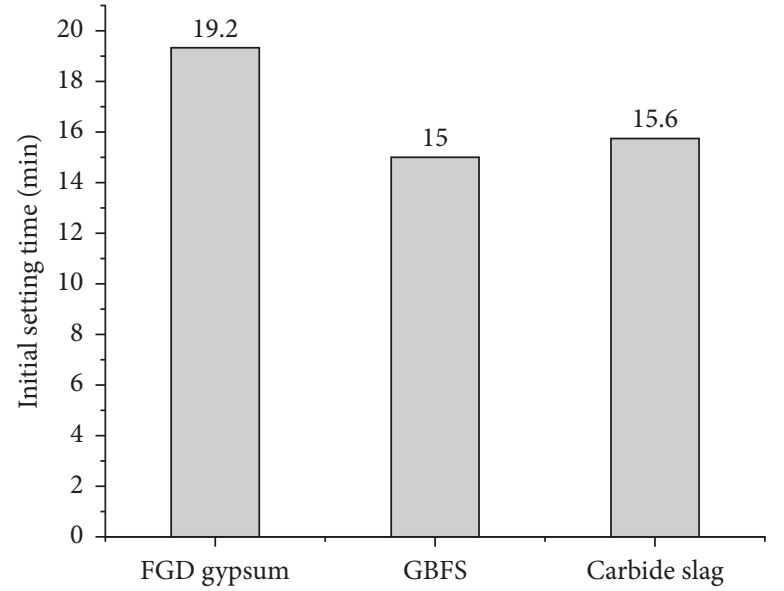

(a)

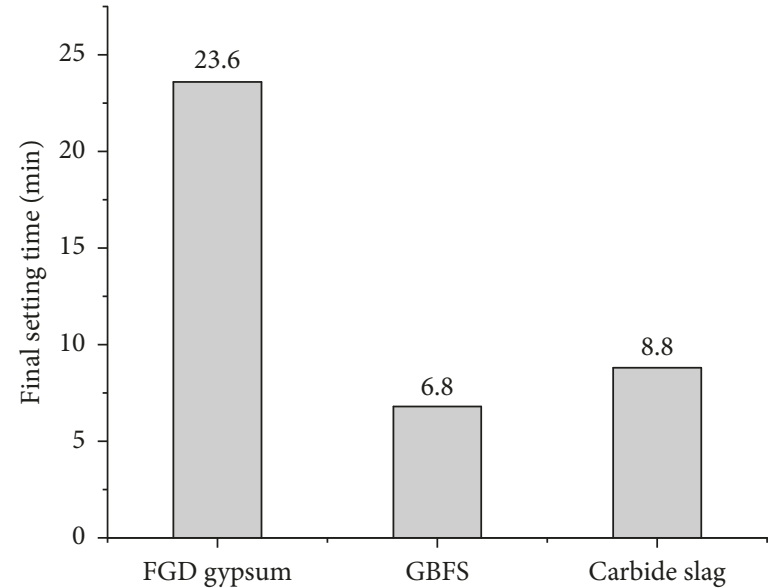

(b)

Figure 6

promote the hydration of fly ash and generate ettringite (AFt) crystals, which in turn cover the surface of fly ash particles, thus decreasing the hydration rate of the cementitious system. As the hydration reaction progresses, the resulting crystallisation pressure produces a significant amount of AFt crystals on the fly ash particle surface. When the crystallisation pressure becomes relatively high, a local rupture of the coated layer occurs, exposing the fly ash particles and further triggering the hydration reaction. Therefore, among the utilised raw materials, FGD gypsum produced the greatest impact on the material setting time. In addition, carbide slag reacted with water to generate calcium hydroxide, which not only provided an alkaline environment for the hydration reaction but also released a large amount of heat, further promoting hydration. Thus, the presence of carbide slag affects the setting time of the prepared cementitious materials to a certain extent.

3.3. Slump Value. Table S3 contains the results of the range analysis conducted for the obtained slump values. It shows that when the raw material combination is $\mathrm{A}_{4} \mathrm{~B}_{1} \mathrm{C}_{5}$ (corresponding to the mass ratio of FGD gypsum: GBFS: carbide slag of $13: 24: 20$ ), it exhibits the greatest impact on the slump of the cementitious material. According to Figure 7, the resulting slump value is affected by the following factors: GBFS > carbide slag > FGD gypsum, because the former is composed of the spherical vitreous bodies with a smooth and compact surface, which ensure good lubrication of the cementitious material. At the same time, the size of GBFS particles is relatively small, which makes them easily dispersible in the matrix. Hence, some amount of the mixing water trapped inside the gap is released; as a result, the presence of GBFS species produces the greatest impact on the slump value of the cementitious material. In addition, the reaction of calcium carbide with water is exothermic and thus accelerates the hydration of cementitious materials (thereby affecting their slump values).

3.4. Strength. According to the data listed in Table 4, the compressive strengths of the cementitious material aged 


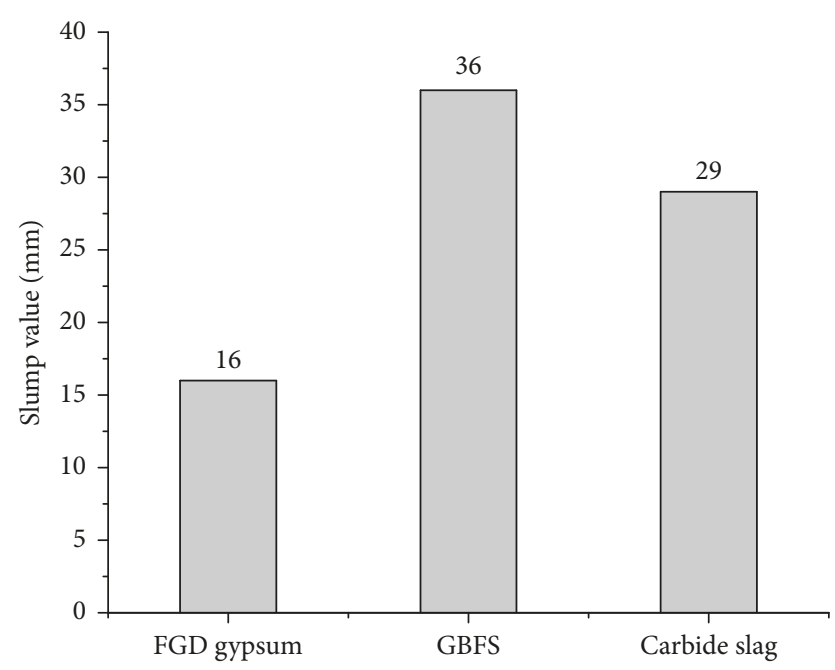

Figure 7

for 7 and $28 \mathrm{~d}$ are equal to 2.48 and $4.07 \mathrm{MPa}$, respectively, and the highest material strength is achieved at mass ratio of FGD gypsum to GBFS to carbide slag of $13: 26: 20$. As indicated by the range analysis results presented in Table S4, at a raw material combination of $\mathrm{A}_{2} \mathrm{~B}_{5} \mathrm{C}_{3}$ (corresponding to the mass ratio of FGD gypsum : GBFS : carbide slag equal to $9: 32: 16$ ), it exhibits the greatest impact on the $7 \mathrm{~d}$ strength of the resulting material. When the compositions of the raw materials are $\mathrm{A}_{4} \mathrm{~B}_{3} \mathrm{C}_{1}$ and $\mathrm{A}_{2} \mathrm{~B}_{3} \mathrm{C}_{5}$ (corresponding to the mass ratios of FGD gypsum : GBFS : carbide slag equal to 13 : $28: 12$ and $9: 28: 20$, resp.), they exhibit the greatest impact on the $28 \mathrm{~d}$ compressive strength and flexural strength of these materials, respectively. The observed phenomenon is due to the effect produced by the presence of silicon dioxide and aluminium oxide species in GBFS; in particular, the $\mathrm{Ca}^{2+}$ ions originated from carbide slag play an important role in the formation of calcium silicate hydrate (C-S-H) gel during the entire hydration process. According to Figures 8 (a) and $8(\mathrm{~b})$, the utilised raw materials can be ranked according to their effect on the $7 \mathrm{~d}$ strength of the cementitious materials as follows: FGD gypsum $>$ GBFS > carbide slag, while the results presented in Figure 8(c) and 8(d) reveal that, after $28 \mathrm{~d}$ of aging, their effects on the flexural and compressive strengths can be described as GBFS > FGD gypsum > carbide slag and GBFS $>$ FGD gypsum $>$ carbide slag, respectively.

In practical applications, the strength of cementitious materials is an important index. To obtain a more accurate ratio of the three raw materials, that is, FGD gypsum, GBFS, and carbide slag, a nonlinear regression analysis was performed on the orthogonal results of the $28 \mathrm{~d}$ compressive strength of the cementitious materials. The following regression equation was obtained:

$$
\begin{aligned}
y= & -0.0011 x_{1}^{2}-0.0141 x_{2}^{2}-0.0043 x_{3}^{2}-0.0165 x_{1} x_{2} \\
& +0.0295 x_{1} x_{3}+0.0221 x_{2} x_{3}+0.0702 x_{1} \\
& +0.6548 x_{2}-0.8262 x_{3},
\end{aligned}
$$

where $y$ indicates the compressive strength, $x_{1}$ indicates FGD gypsum, $x_{2}$ indicates GBFS, and $x_{3}$ indicates carbide slag. Here, the residual sum of squares is 1.469 . The dependent and independent variables in this regression equation are observed to have a good correlation. $P<\alpha$ indicates that this equation can satisfy the significance test. Through accurate prediction, within the range of the value of the three raw material dosages, the optimal ratio of the three raw materials is FGD gypsum:GBFS: carbide slag $=15: 30: 20$, and the compressive strength is $4.2 \mathrm{MPa}$.
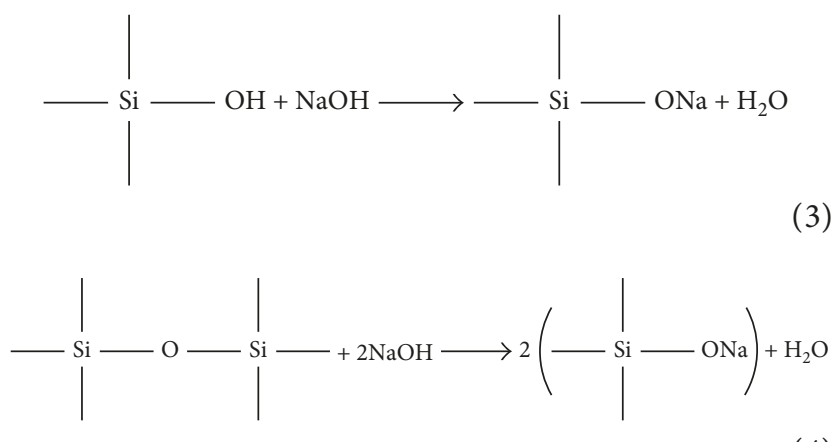

Figure 9 is a hydration mechanism diagram of fly ash. Fly ash and GBFS particles exhibit vitreous structures, which form a compact acidic film during their contact with water. This film prevents the permeation of water into the particles' interior and outward dissolution of ions, thus making it impossible for fly ash and GBFS to undergo hydration. After carbide slag was added to the cementitious system, it reacted with water and raised the temperature of the system. The presence of calcium hydroxide increased the concentration of $\mathrm{OH}^{-}$ions in the mixture, while the addition of the sodium hydroxide activator produced a large amount of $\mathrm{OH}^{-}$ions, which in turn increased its $\mathrm{pH}$. Thus, the addition of carbide slag rapidly destroys the acidic film layers on the fly ash and GBFS surfaces as well as $\mathrm{Si}-\mathrm{O}-\mathrm{Si}$ and Si-O-Al irregular chain structures, which enable the dissolution of various mineral components, such as silicon dioxide and aluminium oxide [28]. The damage of the vitreous surfaces caused by the sodium hydroxide addition can be described by (3) and (4).

The Si-O-Na species produced during these reactions are soluble in water, while the subsequent exchange of $\mathrm{Na}^{+}$with $\mathrm{Ca}^{2+}$ leads to the formation of C-S-H gel. $\beta$-Hemihydrate gypsum can react with water to form calcium sulphate dihydrate. The $\mathrm{SO}_{4}{ }^{2-}$ species produced during the dissociation of calcium sulphate dihydrate are adsorbed onto the surface of the vitreous body, breaking the $\mathrm{Si}-\mathrm{O}$ and $\mathrm{Al}-\mathrm{O}$ bonds at the active reaction sites and thus assisting $\mathrm{OH}^{-}$ions in destroying the acid membrane. In addition, $\mathrm{SO}_{4}{ }^{2-}$ ions react with $\mathrm{AlO}_{2}{ }^{-}$in the reaction system in the presence of $\mathrm{Ca}^{2+}$ ions to form AFt species [3] in accordance with (5).

$\mathrm{SO}_{4}{ }^{2-}+\mathrm{Ca}^{2+}+\mathrm{AlO}_{2}{ }^{-}+\mathrm{OH}^{-} \longrightarrow 3 \mathrm{CaO} \cdot \mathrm{Al}_{2} \mathrm{O}_{3} \cdot 3 \mathrm{CaSO}_{4} \cdot 32 \mathrm{H}_{2} \mathrm{O}$ 


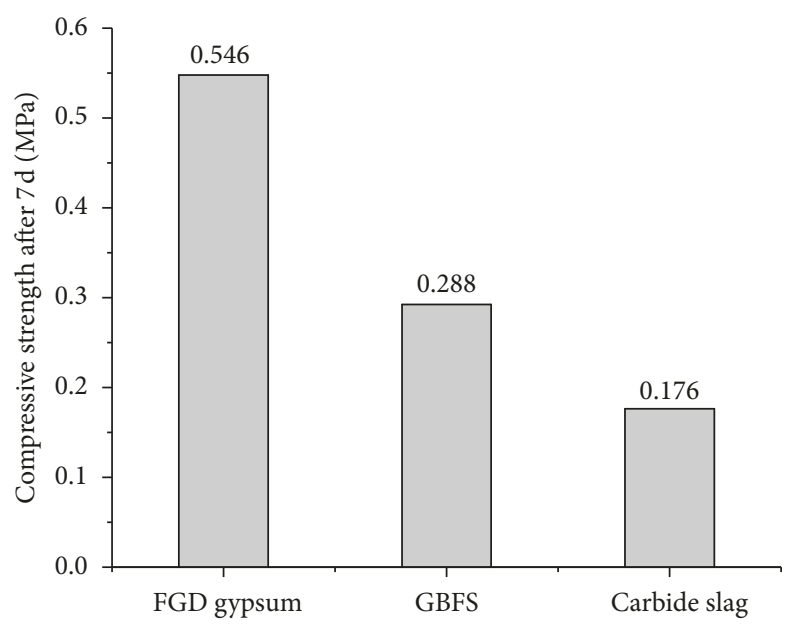

(a)

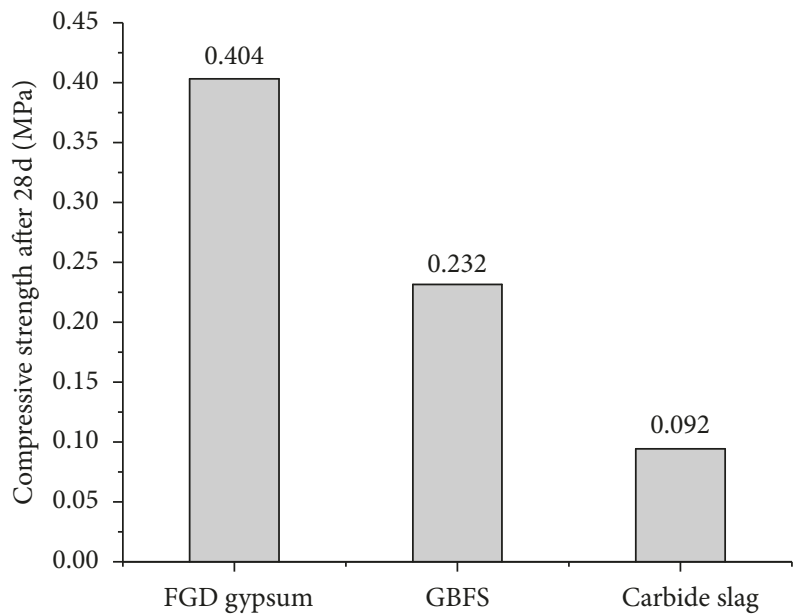

(c)

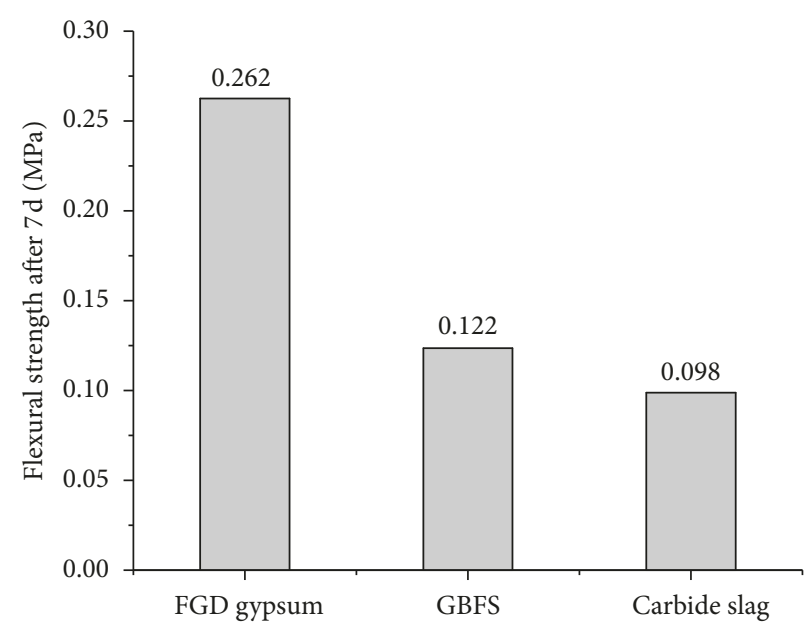

(b)

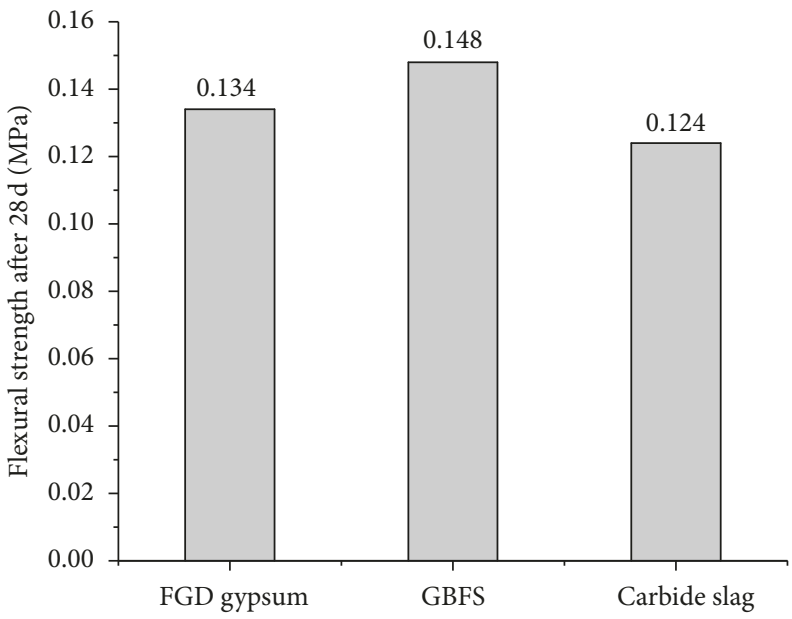

(d)

Figure 8

$$
\begin{gathered}
3 \mathrm{CaO} \cdot \mathrm{Al}_{2} \mathrm{O}_{3} \cdot 6 \mathrm{H}_{2} \mathrm{O}+3 \mathrm{CaSO}_{4} \cdot 2 \mathrm{H}_{2} \mathrm{O}+20 \mathrm{H}_{2} \mathrm{O} \\
\longrightarrow 3 \mathrm{CaO} \cdot \mathrm{Al}_{2} \mathrm{O}_{3} \cdot 3 \mathrm{CaSO}_{4} \cdot 32 \mathrm{H}_{2} \mathrm{O}
\end{gathered}
$$

A fraction of calcium aluminate hydrate can also react with calcium sulphate dihydrate to form AFt in accordance with (6).

The produced AFt species play the following two roles in the obtained cementitious system:

(1) The swelling of AFt [15] cracks the surface of the vitreous body and exposes the active substances located below, thus increasing the concentration of the volcano ash reactants in the system. AFt particles may also fill the gaps in the hydration space, which improves the compactness of the cementitious system and enhances its strength.

(2) The needle-shaped AFt particles interconnect to form fibrous or network coatings on the surfaces of fly ash and blast-furnace slag particles. Because the compactness of the C-S-H layer is greater than that of the AFt coating, the $\mathrm{Ca}^{2+}$ ions produced during calcium hydroxide ionisation tend to diffuse into the interior of the fly ash and blast-furnace slag particles and react with silicon dioxide and aluminium oxide species. This process shortens the plateau of the activation process and further stimulates the activity of fly ash and blast-furnace slag particles.

In addition, $\mathrm{SO}_{4}{ }^{2-}$ ions can displace some of the $\mathrm{SiO}_{4}{ }^{4-}$ ions in the C-S-H gel. The displaced $\mathrm{SiO}_{4}{ }^{4-}$ ion species facilitate further dissolution of aluminium oxide and the reaction with $\mathrm{Ca}^{2+}$ ions, thus increasing the produced gel amount. They can react with the active sites of the $\mathrm{Al}^{3+}$ network on the surface of the vitreous body, cleaving Si-O and $\mathrm{Al}-\mathrm{O}$ bonds and accelerating the hydration reaction [29], which in turn causes the secondary hydration. The active materials of fly ash and blast-furnace slag are consumed in the presence of FGD gypsum and carbide slag, resulting in the establishment of a positive cycle that stimulates their activity to the highest extent possible and, therefore, enhances the strength of the produced cementitious system. 


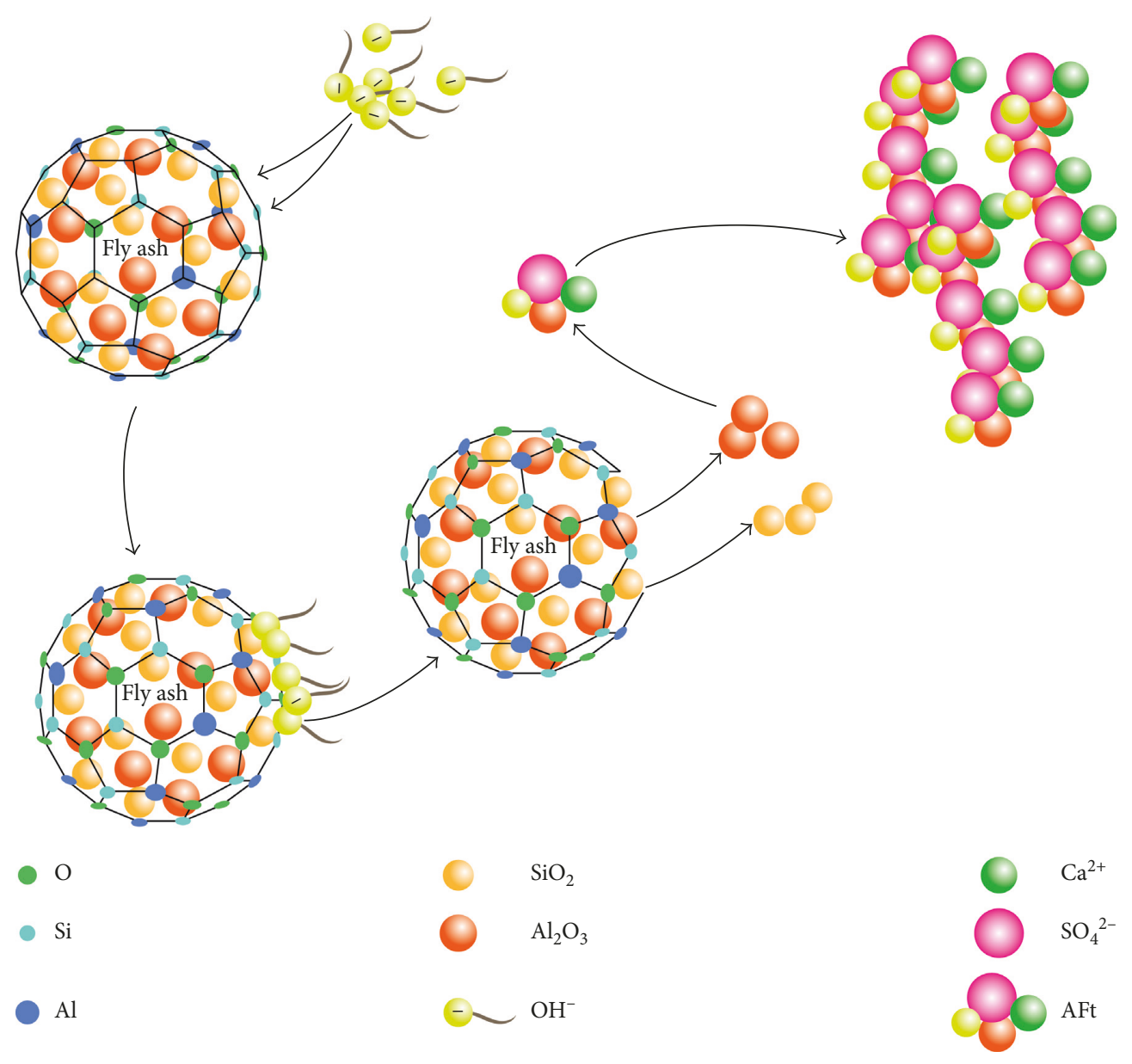

Figure 9

3.5. SEM and XRD Analyses. Figure 10 shows the SEM photographs of the 10th and 21st sets of samples, which contain large amounts of fly ash particles served as a framework. The hydration products of the cementitious material obtained after $7 \mathrm{~d}$ of aging were primarily composed of needle- or rod-like AFt crystals and a small amount of the fibrous C-S-H gel, while the internal sample structure contained relatively large pores. The hydration products obtained after $28 \mathrm{~d}$ of aging included larger amounts of AFt crystals and C-S-H gel, which overlapped and interlaced with each other, thus filling the pores of the cementitious material and forming a relatively compact structure with a continuously increasing strength. Based on the obtained SEM results, sample no. 21 contained smaller amounts of AFt and C-S-H gel species produced during hydration as compared to sample no. 10. Furthermore, sample no. 21 contained a large amount of flaky calcium hydroxide species, which were not involved in the hydration reaction. It also exhibited large pores and an insufficiently compact structure, which was consistent with its strength.

Under the action of carbide slag and sodium hydroxide, active silicon dioxide and aluminium oxide species in the cementitious system reacted with $\mathrm{SO}_{4}{ }^{2-}$ ions in the liquid phase to produce AFt crystals, which in turn filled the pores and bound to the fly ash particles, forming a three-dimensional network spatial structure with a gradually increasing strength [30]. When the fly ash particles were surrounded by the hydration products, they continued to be hydrated into the $\mathrm{C}-\mathrm{S}-\mathrm{H}$ gel and filled the pores of the cementitious system. As a result, the compactness and strength of the resulting cementitious material were enhanced.

Figure 11 shows the XRD pattern obtained for sample no. 10. After the cementitious system underwent hydration for $7 \mathrm{~d}$, several AFt and $\mathrm{CSH}_{2}$ diffraction peaks were detected along with the diffraction peaks of calcium hydroxide, which was not involved in the hydration reaction. The intensities of the calcium hydroxide diffraction peaks gradually decreased with time, while a bulging process accompanied by the formation of a large amount of the $\mathrm{C}-\mathrm{S}-\mathrm{H}$ gel was observed in the $2 \theta$ range of $15-60^{\circ}$. The obtained results indicate that fly ash was gradually activated during the first $7 \mathrm{~d}$ of curing. In addition, prominent $\mathrm{C}-\mathrm{S}-\mathrm{H}$ gel diffraction peaks were observed after $28 \mathrm{~d}$ of hydration, which could be explained as follows: first, aluminium oxide reacted with $\mathrm{Ca}^{2+}$ and $\mathrm{SO}_{4}{ }^{2-}$ ions in the liquid phase to produce AFt crystals (which covered the surface of fly ash particles) and a small amount of the C-S-H gel, which subsequently strengthened the cementitious system. After $28 \mathrm{~d}$ of hydration, a substantial amount of $\mathrm{Ca}^{2+}$ ions were consumed, producing larger amounts of the C-S-H gel. The resulting gel species filled the pores of the cementitious 


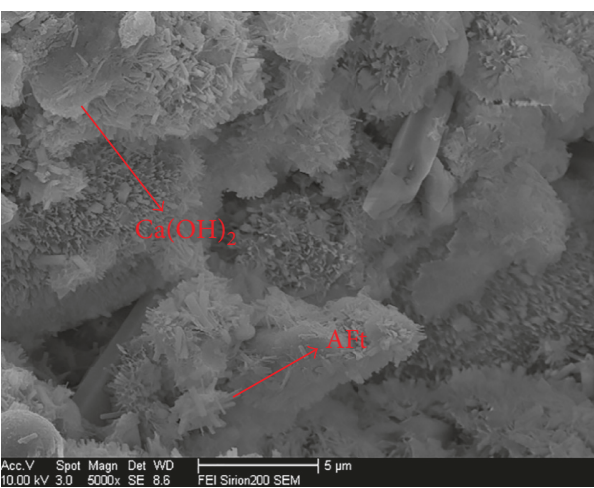

(a)

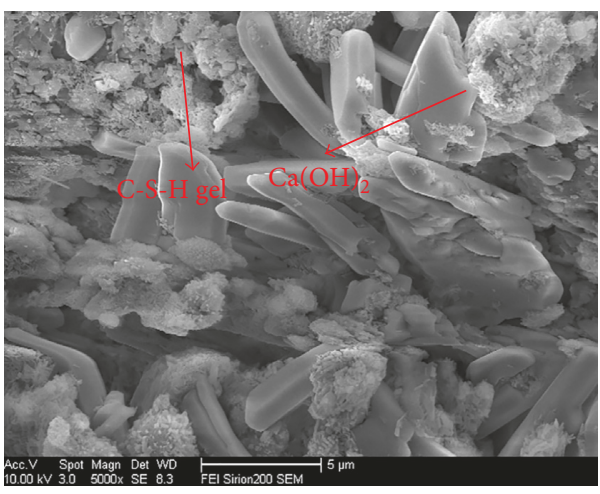

(c)

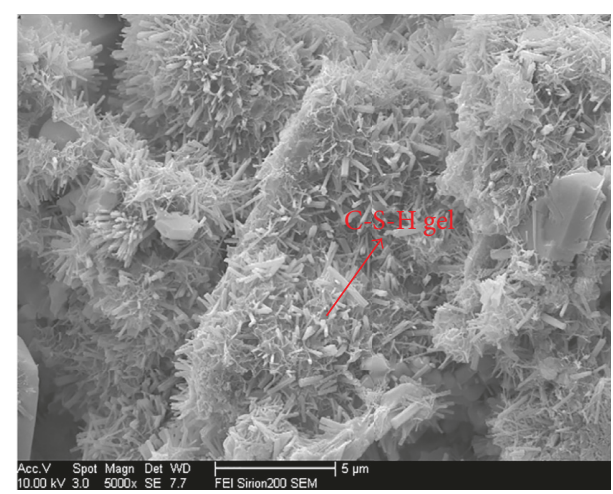

(b)

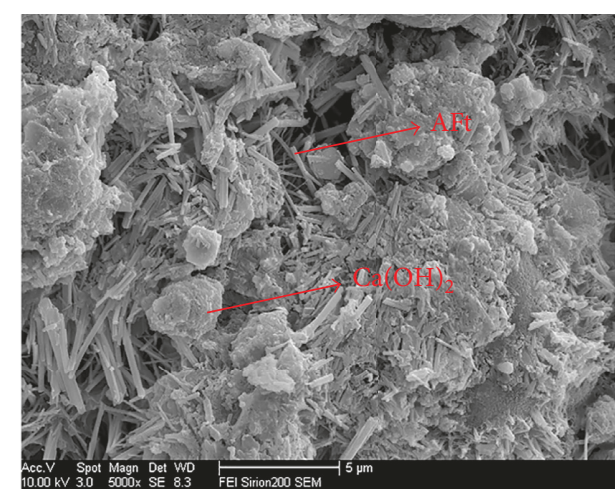

(d)

Figure 10

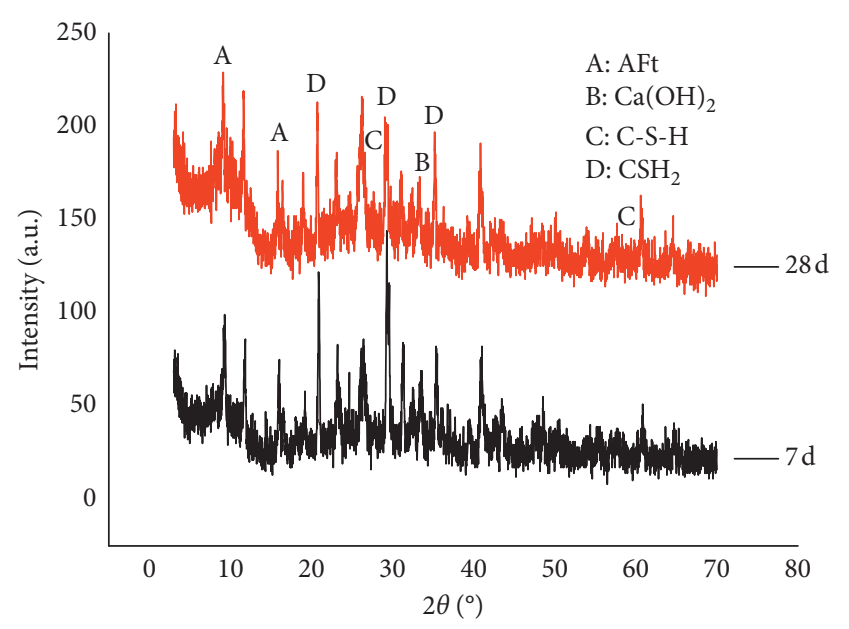

FigURE 11

system and adhered to each other, thereby increasing the material strength.

\section{Conclusion}

In this study, the activity of fly ash and other industrial waste slag was stimulated by the presence of carbide slag in the filling cementitious materials prepared without adding any cement clinker. The main conclusions can be summarised as follows:

(1) The utilised raw materials can be ranked depending on the following parameters: (a) the amount of water consumed for reaching standard consistency and consistency: FGD gypsum > carbide slag > GBFS, (b) the setting time: FGD gypsum > carbide slag $>$ GBFS, (c) the slump value: GBFS $>$ carbide slag $>$ FGD gypsum, (d) the material strength after $7 \mathrm{~d}$ of hydration: FGD gypsum $>$ GBFS $>$ carbide slag, and (e) the material flexural and compressive strengths after $28 \mathrm{~d}$ of hydration: FGD gypsum $>$ GBFS $>$ carbide slag and GBFS > FGD gypsum > carbide slag, respectively.

(2) The optimal activation results were achieved when the mass ratio of carbide slag: fly ash:GBFS: FGD gypsum was $12.1: 60.6: 18.2: 9.1$.

(3) The results of SEM and XRD analyses indicated that the hydration products obtained after $7 \mathrm{~d}$ of curing were primarily composed of AFt crystals and a small amount of the C-S-H gel. In contrast, a relatively large amount of the C-S-H gel was produced after $28 \mathrm{~d}$ of hydration.

(4) The manufacturing of fly ash-carbide slag-GBFS-FGD gypsum cementitious materials utilises substantial amounts of industrial waste (including fly ash and carbide slag), which can potentially produce significant social and economic benefits. 


\section{Data Availability}

The data used to support the findings of this study are included within the supplementary information files.

\section{Conflicts of Interest}

The authors declare that they have no conflicts of interest.

\section{Acknowledgments}

This study was supported by the National Natural Science Foundation of China (Grant nos. 51674038 and 51674157); the Shandong Province Natural Science Foundation (Grant no. ZR2018JL019); the China Postdoctoral Science Foundation (Grant nos. 2014M560567 and 2015T80730); the Shandong Province Science and Technology Development Plan (Grant no. 2017GSF220003); the State Key Program for Coal Joint Funds of the National Natural Science Foundation of China (Grant no. U1261205); the Scientific Research Foundation of Shandong University of Science and Technology for Recruited Talents (Grant nos. 2017RCJJ010 and 2017RCJJ037); the Shandong Province First Class Subject Funding Project (Grant no. 01AQ05202); the Taishan Scholar Talent Team Support Plan for Advantaged \& Unique Discipline Areas; and the Graduate Student Science and Technology Innovation Project of Shandong University of Science and Technology (Grant no. SDKDYC170304).

\section{Supplementary Materials}

Table S1: range analysis of the water amount required for reaching standard consistency and consistency. Table S2: range analysis of the setting time. Table S3: range analysis of the slump value. Table S4: range analysis of the material strength. (Supplementary Materials)

\section{References}

[1] L. J. Gardner, S. A. Bernal, S. A. Walling, C. L. Corkhill, J. L. Provis, and N. C. Hyatt, "Characterisation of magnesium potassium phosphate cements blended with fly ash and ground granulated blast furnace slag," Cement and Concrete Research, vol. 74, pp. 78-87, 2015.

[2] J. L. Pastor, J. M. Ortega, M. Flor, M. Pilar López, I. Sánchez, and M. A. Climent, "Microstructure and durability of fly ash cement grouts for micropiles," Construction and Building Materials, vol. 117, pp. 47-57, 2016.

[3] G. Y. Chen and W. H. Huang, "Investigation on blending CFB ash with blast furnace slag as replacement for Portland cement used in concrete binders," Advanced Materials Research, vol. 723, pp. 623-629, 2013.

[4] Y. Chen and Y. L. Gao, "Fly ash-desulfurization gypsum mortar and concrete part II: performances," Advanced Materials Research, vol. 243-249, pp. 6880-6886, 2011.

[5] G. Rutkowska, K. Wiśniewski, M. Chalecki, M. Górecka, and K. Miłosek, "Influence of fly-ashes on properties of ordinary concretes," Annals of Warsaw University of Life SciencesSGGW Land Reclamation, vol. 48, no. 1, pp. 79-94, 2016.

[6] J. A. Zakeri, M. Esmaeili, S. A. Mosayebi, and O. Sayadi, "Experimental investigation of the production of sleepers from concrete that contains blast furnace slag," Proceedings of the Institution of Mechanical Engineers Part F Journal of Rail and Rapid Transit, vol. 230, no. 1, pp. 77-84, 2016.

[7] N. Marjanović, M. Komljenović, Z. Baščarević, V. Nikolić, and R. Petrović, "Physical-mechanical and microstructural properties of alkali-activated fly ash-blast furnace slag blends," Ceramics International, vol. 41, no. 1, pp. 1421-1435, 2015.

[8] X. L. Guo, H. S. Shi, and A. D. Warren, "Utilization of thermally treated flue gas desulfurization (FGD) gypsum and class-C fly ash (CFA) to prepare CFA-based geopolymer," Journal of Wuhan University of Technology, vol. 28, no. 1, pp. 132-138, 2013.

[9] P. Pavithra, M. S. Reddy, P. Dinakar, B. Hanumantha Rao, B. K. Satpathy, and A. N. Mohanty, "A mix design procedure for geopolymer concrete with fly ash," Journal of Cleaner Production, vol. 133, pp. 117-125, 2016.

[10] H. Y. Du, L. N. Yang, W. Q. Gao et al., "Effects of characteristics of fly ash on the properties of geopolymer," Transactions of Tianjin University, vol. 22, no. 3, pp. 261-267, 2016.

[11] W. X. Chen, F. Y. Li, X. H. Guan, L. Chen, and W. Bo Nie, "Research on mining water-rich fly-ash-based filling material," Advanced Materials Research, vol. 988, pp. 201-206, 2014.

[12] S. G. Hu, X. J. Lu, H. L. Niu, and Z. Q. Jin, "Research on preparation and properties of backfilling cementation material based on blast furnace slag," Advanced Materials Research, vol. 158, pp. 189-196, 2011.

[13] B. Ma, X. Li, Y. Mao, and X. Shen, "Synthesis and characterization of high belite sulfoaluminate cement through rich alumina fly ash and desulfurization gypsum," Ceramics Silikaty, vol. 57, no. 1, pp. 7-13, 2013.

[14] A. Sarkar, A. K. Sahani, D. K. Singha Roy, and A. Kr Samanta, "Compressive strength of sustainable concrete combining blast furnace slag and fly ash," Social Science Electronic Publishing, vol. 9, no. 1, pp. 17-26, 2016.

[15] H. Qin, X. Liu, and G. Li, "Preparation and properties of desulfurization gypsum-slag hydraulic cementitious materials," Procedia Engineering, vol. 27, pp. 244-252, 2012.

[16] Y. L. Wang, S. J. Dong, L. L. Liu, S. P. Cui, and H. B. Xu, "Study formation process of cement clinker minerals by using calcium carbide slag as raw material," Applied Mechanics \& Materials, vol. 389, pp. 341-345, 2013.

[17] C. W. Hao and M. Deng, "Surface modification of fly ashes with carbide slag and its effect on compressive strength and autogenous shrinkage of blended cement pastes," Journal of Wuhan University of Technology-Mater Sci Ed, vol. 27, no. 6, pp. 1149-1153, 2012.

[18] Q. Zhang, X.-M. Hu, M.-Y. Wu, Y.-Y. Zhao, and C. Yu, "Effects of different catalysts on the structure and properties of polyurethane/water glass grouting materials," Journal of Applied Polymer Science, vol. 135, no. 27, 2018.

[19] G. Zhou, Q. Zhang, R. Bai, T. Fan, and G. Wang, "The diffusion behavior law of respirable dust at fully mechanized caving face in coal mine: CFD numerical simulation and engineering application," Process Safety and Environmental Protection, vol. 106, pp. 117-128, 2017.

[20] G. Zhou, Y. Ma, T. Fan, and G. Wang, "Preparation and characteristics of a multifunctional dust suppressant with agglomeration and wettability performance used in coal mine," Chemical Engineering Research and Design, vol. 132, pp. 729-742, 2018.

[21] W. Yang, H. Wang, B. Lin et al., "Outburst mechanism of tunnelling through coal seams and the safety strategy by using "strong-weak" coupling circle-layers," Tunnelling and Underground Space Technology, vol. 74, pp. 107-118, 2018. 
[22] H. Wang, W. Nie, W. Cheng, Q. Liu, and H. Jin, "Effects of air volume ratio parameters on air curtain dust suppression in a rock tunnel's fully-mechanized working face," Advanced Powder Technology, vol. 29, no. 2, pp. 230-244, 2017.

[23] Q. Liu, W. Nie, Y. Hua et al., "The effects of the installation position of a multi-radial swirling air-curtain generator on dust diffusion and pollution rules in a fully-mechanized excavation face: a case study," Powder Technology, vol. 329, pp. 371-385, 2018.

[24] W. Nie, W. Wei, Q. Liu et al., "Simulation experiments on the controllability of dust diffusion by means of multi-radial vortex airflow," Advanced Powder Technology, vol. 29, no. 3, pp. 835-847, 2018.

[25] T. Fan, G. Zhou, and J. Wang, "Preparation and characterization of a wetting-agglomeration-based hybrid coal dust suppressant," Process Safety and Environmental Protection, vol. 113, pp. 282-291, 2018.

[26] Z. X. Hu, X. M. Hu, W. M. Cheng, and W. Lu, "Influence of synthetic conditions on the performance of melaminephenol-formaldehyde resin microcapsules," High Performance Polymers, 2018.

[27] W. M. Cheng, X. M. Hu, J. Xie, and Y. Zhao, "An intelligent gel designed to control the spontaneous combustion of coal: fire prevention and extinguishing properties," Fuel, vol. 210, pp. 826-835, 2017.

[28] X. L. Guo, H. S. Shi, L. Chen, and W. A. Dick, "Alkaliactivated complex binders from class $\mathrm{C}$ fly ash and Cacontaining admixtures," Journal of Hazardous Materials, vol. 173, no. 1-3, pp. 480-486, 2010.

[29] F. S. Fonseca, R. C. Godfrey, and K. Siggard, "Compressive strength of masonry grout containing high amounts of class $\mathrm{F}$ fly ash and ground granulated blast furnace slag," Construction and Building Materials, vol. 94, pp. 719-727, 2015.

[30] Z. X. Hu, X. M. Hu, W. M. Cheng et al., "Performance optimization of one-component polyurethane healing agent for self-healing concrete," Construction and Building Materials, vol. 179, pp. 151-159, 2018. 


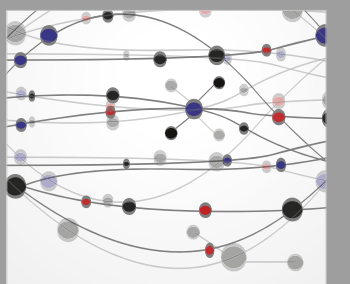

The Scientific World Journal
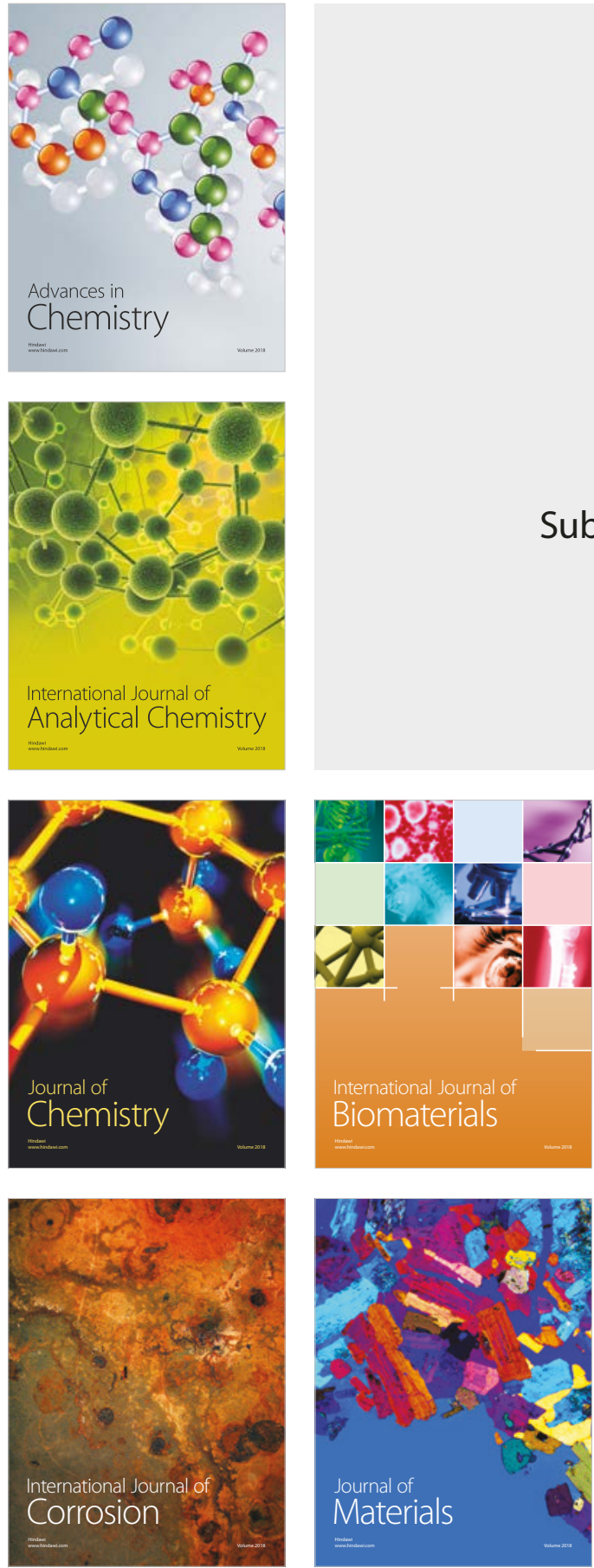

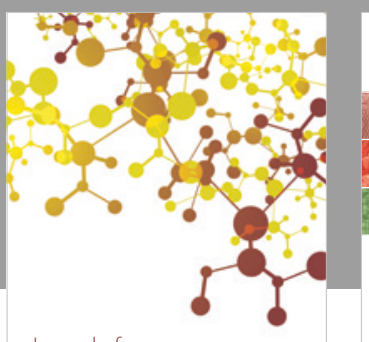

Journal of

Applied Chemistry
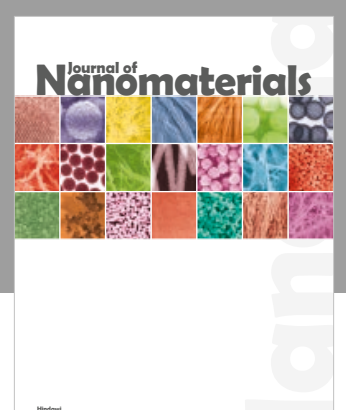

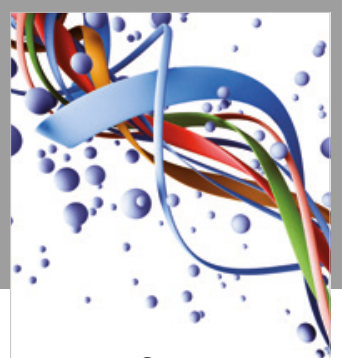

Scientifica

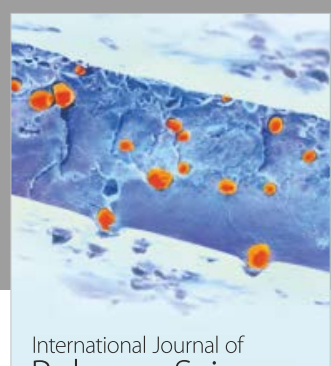

Polymer Science

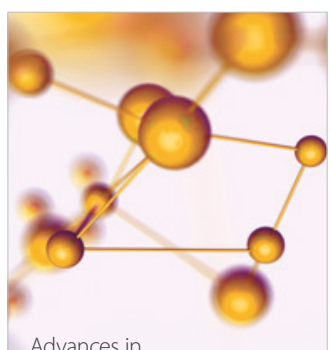

Physical Chemistry
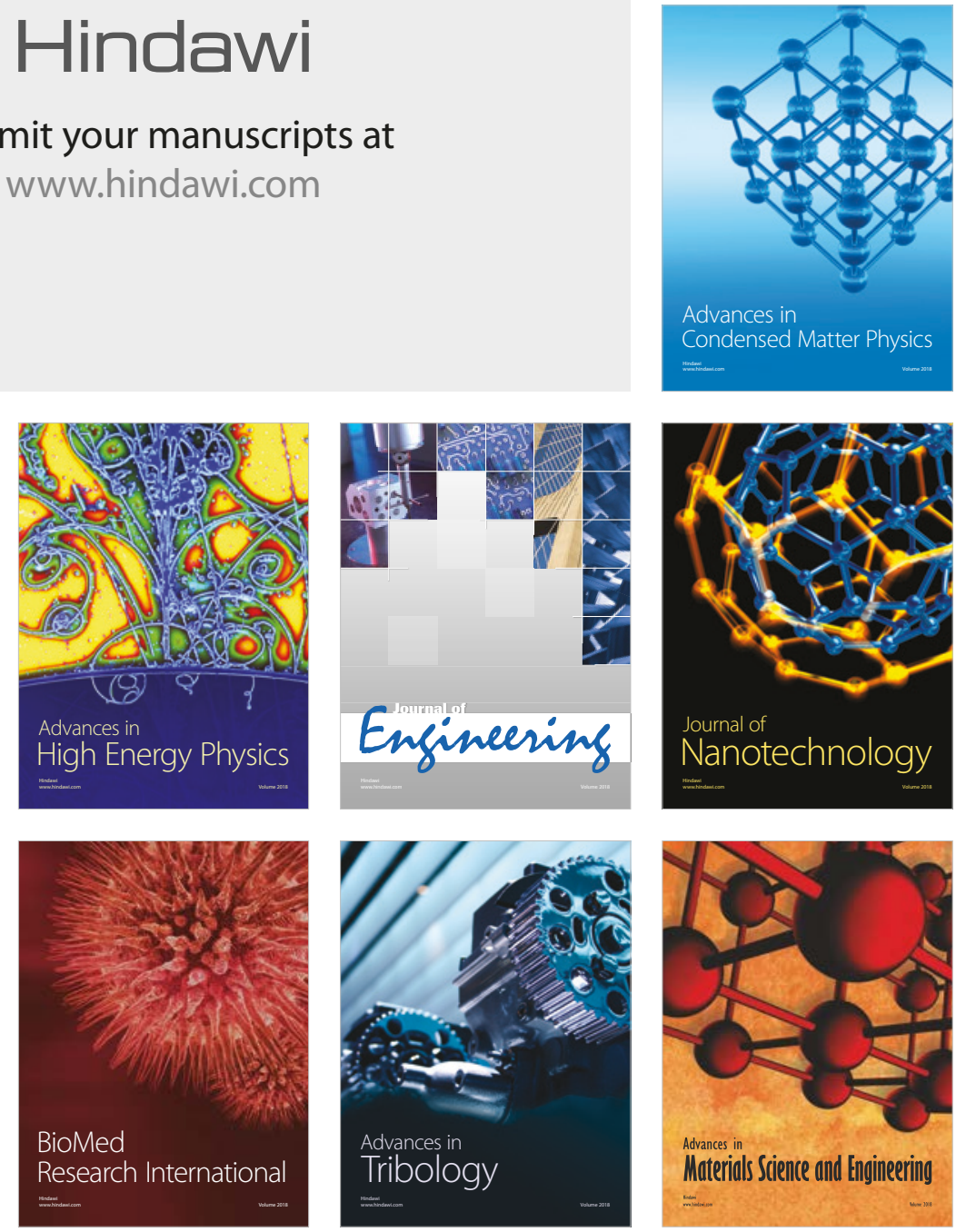